\title{
TRATAMIENTO DE LA DEPENDENCIA DEL TABACO EN UN FUMADOR QUE HA TENIDO UN CÁNCER DE PULMÓN
}

\author{
TREATMENT OF TOBACCO DEPENDENCE IN A SMOKER WHO HAS HAD LUNG \\ CANCER IN THE PAST
}

Bárbara Piñeiro y Elisardo Becoña

Unidad de Tabaquismo, Facultad de Psicología, Universidad de Santiago de Compostela

Resumen

La relación entre fumar y el cáncer de pulmón está bien establecida. La principal causa conocida del cáncer de pulmón es el consumo de tabaco, que es el responsable del $90 \%$ de los casos de cáncer de pulmón. En el presente artículo presentamos el caso de un fumador que ha tenido un cáncer de pulmón en el pasado (superviviente de doce años de un adenocarcinoma de pulmón), que demanda tratamiento para dejar de fumar por el miedo a padecer otro cáncer de pulmón y a morir por las enfermedades relacionadas con el consumo de tabaco. Se le aplicó el tratamiento psicológico cognitivo-conductual "Programa Para Dejar de Fumar". Se describe la evaluación, tratamiento y seguimientos realizados durante doce meses. El resultado del tratamiento muestra que es posible dejar de fumar y mantenerse abstinente a lo largo de un año. También manifiesta claros beneficios del abandono del tabaco a nivel físico, psicológico y en su aumento de la calidad de vida relacionada con la salud.

Palabras clave: Fumar, cáncer de pulmón, tratamiento psicológico, dejar de fumar.

\section{Abstract}

The relationship between smoking and lung cancer is well established. The leading known cause of lung cancer is the consumption of tobacco, which is responsible for $90 \%$ of lung cancer cases. In this article we present the case of a smoker who has had lung cancer in the past (survivor of lung adenocarcinoma a total of twelve years), who requires treatment to stop smoking, motivated by the fear of suffering from lung cancer again and dying from diseases related to the consumption of tobacco. He was given the cognitive-behavioral psychological treatment "Smoking Cessation Program." It describes the assessment, treatment and subsequent follow-ups over twelve months. The result of this treatment shows that it is possible to quit smoking and remain abstinent from it during a year. This case highlights the physical and psychological benefits of quitting smoking, as well as the increase of healthrelated quality of life.

Key words: Smoking, lung cancer, psychological treatment, smoking cessation.

\section{Correspondencia:}

Bárbara Piñeiro Neiro,

Unidad de Tabaquismo, Departamento de Psicología Clínica y Psicobiología,

Facultad de Psicología, Universidad de Santiago de Compostela.

Campus Universitario Sur. 15782 Santiago de Compostela.

E-mail: barbara.pineiro@usc.es

Fuente de financiación:

El presente trabajo ha sido financiado por el Ministerio de Ciencia e Innovación (Programa Nacional de Proyectos de Investigación Fundamental, proyecto PSI2008-02597/PSIC). Bárbara Piñeiro es beneficiaria de una ayuda Predoctoral de Formación de Personal Investigador (FPI) del Ministerio de Ciencia e Innovación, Ref-BES-2009-012929. 


\section{INTRODUCCIÓN}

Hace décadas que se conocen las consecuencias del tabaco en la salud ${ }^{(1)}$. Sabemos que existe una clara asociación entre fumar y distintas enfermedades (EPOC, cánceres, cardiopatías, etc.). La mortalidad que produce el tabaco constituye el mayor problema de salud prevenible en los países desarrollados. El 30\% de las muertes por cáncer se atribuyen directamente al consumo de tabaco ${ }^{(2,3)}$, entre los que destacan el cáncer de la cavidad oral y faríngea, cáncer de laringe, cáncer de tráquea, bronquios y pulmón, cáncer de esófago, cáncer de estómago, cáncer de páncreas, cáncer de vejiga, cáncer de riñón y cáncer de cuello de útero ${ }^{(4,5)}$. Además, los fumadores pasivos, que se ven expuestos frecuentemente al humo del tabaco (como las parejas de los fumadores), tienen también un mayor riesgo de padecer cáncer de pulmón ${ }^{(3)}$.

Actualmente, el tabaquismo representa la primera causa evitable de enfermedad y muerte prematura en el mundo y es responsable de 5.000.000 de muertes anuales, cifra que podría duplicarse en el año $2030^{(6)}$. En nuestro país, la mortalidad atribuible al consumo de tabaco es muy elevada, situándose en torno a las 50.000 personas cada año $0^{(7,8)}$.

En relación a los cánceres, destaca el de pulmón con el que el tabaco guarda una relación causal(9) explicando su consumo el $90 \%$ de estos cánceres ${ }^{(9-11)}$. El riesgo de desarrollar cáncer de pulmón aumenta en función del número de cigarrillos que se fuma y del tiempo que se lleve fumando. De este modo, dejar de fumar, sea cual sea la edad a la que se logre, evita que aumente el riesgo de cáncer de pulmón, pero cuanto antes se deje, mayores serán los beneficios ${ }^{(9)}$.

El cáncer de pulmón es la neoplasia más frecuente en la actualidad en los países industrializados y la primera causa de muerte por cáncer en el mundo ${ }^{(9,12)}$. Aun- que predomina en varones en la mayoría de los países del mundo, en EE. UU. ya representa la primera causa de muerte por cáncer en las mujeres ${ }^{(5)}$. En España, la mortalidad es mucho más elevada en el sexo masculino, si bien, en la última década la tendencia ha sido a estabilizarse en varones y a incrementarse en las mujeres ${ }^{(7,8,13)}$. De hecho, la mortalidad por cáncer de pulmón muestra una tendencia creciente en las mujeres en varios países europeos $^{(14)}$. Especialmente, en los jóvenes europeos, la mortalidad por cáncer de pulmón está convergiendo entre hombres y mujeres debido al aumento en el consumo de tabaco en las mujeres ${ }^{(15)}$. Por lo demás, la incidencia y la mortalidad son muy similares porque el diagnóstico continúa realizándose en fases avanzadas de la enfermedad ${ }^{(16)}$.

Las patologías pulmonares se clasifican en benignas y malignas, representando el $90 \%$ de todos los tumores ${ }^{(17,18)}$. El cáncer de pulmón puede dividirse en dos grandes grupos según el tipo de células que lo forman: el de cáncer de células pequeñas o microcíticas (CPCM) y, el más frecuente, el cáncer de células no pequeñas o no microcíticas (CPCNM), al cual pertenecen entre el 75 al $80 \%$ de los cánceres de pulmón ${ }^{(19)}$. Este último, a su vez, se divide en subgrupos histológicos: a) carcinoma de células escamosas o carcinoma epidermoide, b) adenocarcinoma (carcinoma bronquioalveolar) y c) carcinoma de células gigantes $^{(20)}$.

EI CPCM lleva a un desarrollo temprano de metástasis regional y a distancia $y$, por lo tanto, tiende a ser agresivo. Por el contrario, el CPCNM tiene un crecimiento más lento y es menos invasivo, especialmente el subtipo escamoso ${ }^{(21)}$. Los cánceres tipo CPCM son usualmente tratados con regímenes quimioterapéuticos. Por el contrario, los de tipo CPCNM son tratados quirúrgicamente en estadios tempranos (I, II, hasta III), incluso, en algunas 
ocasiones, se intervienen metástasis pulmonares dependiendo del tamaño y sitio del tumor ${ }^{(22)}$.

Una de las razones por las cuales el cáncer de pulmón está asociado a una alta mortalidad es que es difícil hacer un diagnóstico temprano. Esto permite que el tumor crezca sustancialmente antes de volverse sintomático ${ }^{(23)}$. Su pronóstico grave se debe en parte al hecho de que el carcinoma de pulmón es frecuentemente diagnosticado en estadios tardíos con una tasa de supervivencia a 5 años del $6 \%$ al $16 \%$ en Europa y una tasa menos favorable para personas con carcinoma de células peque$\tilde{n ̃ a s}^{(24)}$. La supervivencia a 5 años de toda la población diagnosticada es del $15 \%{ }^{(25)}$. El $70 \%$ de los diagnosticados se hacen en estadios tardíos $^{(25)}$. A su difícil diagnóstico temprano y a la escasez de procedimientos efectivos de cribado se debe la alta mortalidad de esta enfermedad ${ }^{(26)}$.

Dejar de fumar supone una mejoría importante en la calidad de vida de los fumadores; por ejemplo, el riesgo de morir de cáncer de pulmón es similar al de los no fumadores al cabo de diez años después de dejar de fumar, al igual que la probabilidad de padecer cáncer de boca, de laringe, de esófago, de vejiga, de riñón y de páncreas ${ }^{(27)}$. Además, disminuye la probabilidad de padecer una enfermedad arterial periférica, se reduce el número de infartos agudos de miocardio y la mortalidad post-infarto, así como disminuye la probabilidad de padecer ictus isquémicos y hemorragias cerebrales ${ }^{(28,5)}$.

En pacientes con cáncer de pulmón dejar de fumar tiene efectos positivos muy significativos, como la disminución del riesgo de la enfermedad, el aumento del tiempo de supervivencia, la disminución de las complicaciones quirúrgicas y del postoperatorio, la reducción de las complicaciones de la radioterapia, una mayor tolerancia y resistencia al ejercicio y una mejora significativa de la calidad de vida, incrementando los niveles de actividad y movilidad $^{(29,30)}$.

Por el contrario, seguir fumando cigarrillos en pacientes supervivientes de cáncer de pulmón está relacionado con un déficit en las medidas de calidad de vida relacionada con la salud ${ }^{(30)}$. De hecho, la continuidad en el consumo de tabaco en personas que han sufrido cáncer de pulmón puede reducir su supervivencia, incrementar el riesgo de la aparición de un segundo tumor y disminuir la efectividad del tratamiento médico para ese cáncer, así como una pérdida en la calidad de vida $^{(30-34)}$. Sabemos, además, que los efectos positivos de la cesación se observan en lo que se refiere a la aparición de un segundo cáncer primario relacionado con el tabaco, en pacientes con un carcinoma de células pequeñas, que han sobrevivido al tratamiento por un período mínimo de dos años ${ }^{(35)}$.

En base a todo lo anterior, consideramos relevante ayudar a cualquier fumador, y en especial a aquel que ha tenido cáncer de pulmón, a dejar de fumar y así evitar que aumente el riesgo de padecer cáncer de pulmón.

El caso que presentamos a continuación es el de un fumador diagnosticado y tratado de cáncer de pulmón hace 12 años (en el año 2000), que ha vuelto a fumar. Demanda tratamiento para dejar de fumar motivado por el miedo a una recurrencia o recidiva del desarrollo del cáncer de pulmón y, también, por miedo a las enfermedades relacionadas con el consumo de tabaco.

\section{DESCRIPCIÓN DEL CASO}

M. C. C. es un varón de 53 años, casado y con 3 hijos. Realizó estudios universitarios, cursando Derecho. Trabaja en una compañía multinacional.

Hace 12 años le diagnosticaron cáncer de pulmón (concretamente, adenocarcino- 
ma). En el momento del diagnóstico, su cáncer se encontraba en el estadio I, es decir, el cáncer se encontraba únicamente en el pulmón y estaba rodeado por tejido normal. Se detectó en los primeros estadios de la enfermedad y, por lo tanto, el pronóstico era favorable.

En el momento de la evaluación (2011), M. C. C. fuma 10 cigarrillos diarios de Winston Rojo, una marca alta en nicotina $(0,8 \mathrm{mg})$. Una de las razones que le lleva a acudir a tratamiento para dejar de fumar es que, debido a la enfermedad que tiene (lobotomía del lóbulo superior derecho del pulmón debido a un adenocarcinoma), no debería de seguir fumando. Tiene mucho miedo a las enfermedades relacionadas con el consumo de tabaco, especialmente, a padecer cáncer de pulmón o a sufrir una recidiva del tumor que ya tuvo en el pasado.

Es indudable que el diagnóstico de una patología, sobre todo cuando ésta es atribuible al tabaco, en este caso cáncer de pulmón, desempeña un papel decisivo en la motivación del fumador para dejar de fumar.

\section{Evaluación}

En el primer contacto se tuvo una entrevista con M. C. C. y se le aplicaron varios cuestionarios sobre el consumo de tabaco y aspectos psicológicos relacionados con el mismo. A través de la entrevista clínica conocimos cómo se detectó, trató y desarrolló su cáncer. La demanda de tratamiento a la que nos referimos la hizo en enero de 2011.

M. C. C. relata que en el año 2000, realizando tareas de jardinería en su huerta, sintió fuertes dolores en el pecho. Al principio pensó que sería un dolor muscular, pero al ver que al cabo de dos días los dolores no remitían, acudió a su médico de familia porque tenía miedo de que fuese un infarto. En el centro de salud le realizaron las pruebas pertinentes para descartar que pudiese tratarse de un infarto y como el electrocardiograma y demás pruebas habían sido correctas, le enviaron a hacerse una radiografía del tórax. En esta prueba, los médicos informaron a M. C. C. que tenía "una cosa que no pintaba bien en el lóbulo superior derecho" y siguieron realizándole más pruebas. Al final le diagnosticaron un adenocarcinoma y la mejor opción que encontraron fue aplicar cirugía. Además, el oncólogo le dijo tajantemente "tiene usted que dejar de fumar". Por aquel entonces M. C. C fumaba alrededor de dos cajetillas diarias de cigarrillos de la marca Ducados Negro (0,8 mg. de nicotina).

M. C. C. empezó a fumar a los 13 años mientras estudiaba. Fumaba pocos cigarrillos al día, 2 o 3, y eran cigarrillos sin filtro, cigarrillos "Celtas". La conducta de fumar en su casa era algo normal y habitual "como tomar el desayuno por la mañana" decía. Vivía con su padre y sus tres hermanos también fumadores y era su padre el que compraba cigarrillos para todos. Desde el momento en que empezó a trabajar, a los 24 años, su consumo de cigarrillos fue en aumento, pasó de fumar una cajetilla de ducados negro a dos cajetillas diarias, así, hasta el año 2000 en el que le detectaron el cáncer de pulmón.

Al preguntarle por el recuerdo tras la comunicación del diagnóstico de cáncer de pulmón y de cómo se sintió cuando el oncólogo le dijo que tenía que dejar de fumar, M. C. C. comenta que no se asustó del diagnóstico porque le habían dicho que lo habían descubierto en una fase muy temprana y tendría buen pronóstico. En cuanto a dejar de fumar, comenta que no le costó en absoluto porque su miedo a morir era mayor que seguir fumando. No le resultó difícil el abandono porque al hacerle la cirugía permaneció en el hospital una semana y, después de la operación, tuvo muchos y muy fuertes dolores en el pecho. Por lo tanto no se acordaba del ta- 
baco para nada. Recordando los síntomas del post operatorio, M. C. C. indica que del sentimiento que más se acuerda es de la "sensación de vació que noté en el pecho" y "muchísimo dolor".

Al preguntarle por la incidencia del diagnóstico y de la enfermedad en la familia y en el trabajo, nos comenta que debido a que los médicos decían que el pronóstico sería bueno su mujer lo llevó bien, "ella es muy fuerte". Además, estaba contenta porque a ella no le gustaba que fumase, y se alegró de que acabase con "ese vicio". En el trabajo estuvo 3 semanas de baja y como su puesto era de dirección y supervisión, y no implicaba trabajo físico, se reincorporó rápido. Ahí fue cuando más recordó el tabaco porque era donde fumaba, puesto que en casa no podía fumar, pues su mujer se lo tenía prohibido.

Relata la época de la recuperación y rehabilitación como la peor, ya que le costaba mucho esfuerzo y sentía mucho dolor. Tuvo que realizar muchos ejercicios de respiración tratando de recuperar y aumentar su capacidad pulmonar, la cual tenía disminuida después de la lobotomía. Era lo que peor llevaba. Notaba que se ahogaba constantemente, que respiraba mal, que tenía mucha tos, y a raíz de estos síntomas empezó a coger mucho miedo a morir ahogado y asfixiado. Empezó a no dormir, al principio por el dolor, y después, por miedo a morir por no dar respirado.

Al relatar sus problemas para dormir, M. C. C. nos cometa "me quitaron un problema pero me metieron otro". Desde que le extirparon el lóbulo superior derecho se enganchó a las benzodiacepinas: Ileva 10 años tomando "la pastilla para dormir". Relata que desde la operación era incapaz de conciliar el sueño, se levantaba muy fatigado, cansado y que eso le generaba malestar durante el día, puesto que así no podía rendir bien en el trabajo. Además, por esa misma época empezó a beber alcohol, "más de lo que era habitual en mí", "era lo único que podía calmar mi ansiedad y mi miedo".

La causa que le llevó a recaer en el tabaco después de estar 6 años abstinente fue que en el año 2006, después de acudir al psiquiatra a por la dosis de "su pastilla para dormir", éste le dijo que si no había un problema aparente y se encontraba bien, que tenía que dejarlas. A raíz de ahí y de ir bajando la dosis, M. C. C. volvió a tener problemas para dormir, le dolía la cabeza, se mareaba y le picaba el cuerpo. A causa de estos síntomas, un día decidió ir a comprar un paquete de cigarrillos para eliminar esa ansiedad y ese malestar que tenía.

Una vez finalizada la entrevista le aplicamos varios cuestionarios sobre el consumo de tabaco y aspectos psicológicos relacionados con el mismo.

A través del Cuestionario sobre el hábito de fumar ${ }^{(36)}$ se recogió información sobre variables sociodemográficas, características del consumo de tabaco, intentos previos de abandono del consumo o reducción del mismo durante el último año, razones para dejar de fumar, creencias sobre las consecuencias del consumo de tabaco en la salud, enfermedades o síntomas relacionados con el tabaco que ha padecido o padece, consumo del alcohol, café, té y medicamentos.

Al preguntarle por intentos previos de abandono, indica que acudió en el año 1992 a la Asociación Española Contra el Cáncer porque su mujer se había quedado embarazada y no quería que fumase al nacer la hija. Otro intento fue en el año 2008 con este mismo tratamiento y el último intento de abandono fue en el año 2011 (esta última evaluación). Indica que nadie de su entorno sabía que había vuelto a fumar desde que logró la abstinencia en el año 2008. En el primer intento de abandono (1992) no logró la abstinencia porque "no estaba suficientemente motivado, fui a tratamiento porque me lo pidió mi mu- 
jer y acudí para no llevarle la contraria". En el segundo intento de abandono alcanzó la abstinencia en la quinta sesión y se mantuvo año y medio abstinente (desde febrero de 2008 hasta agosto de 2009). Al preguntarle por la situación de recaída en el tabaco, comenta que se produjo a raíz de "problemas" que le generaban ansiedad y nerviosismo. Dice que fumando calmaba esa ansiedad y esa sensación de malestar que tenía.

De la evaluación realizada en esta última ocasión (2011) obtuvimos la siguiente información: M. C. C. es fumador habitual desde los 13 años, inhala el humo al fumar, le da muchas caladas al cigarrillo y los fuma enteros hasta el filtro. En el último año el número máximo de cigarrillos fumados al día fue de 12 debido a problemas en el trabajo. En años anteriores fumaba 40 cigarrillos diarios, aunque no lo achaca a ninguna ocasión especial, simplemente "era mi forma de fumar habitual hasta que me detectaron la enfermedad".

Vive con su mujer y sus tres hijas de 20, 18 y 15 años, ninguna de ellas fumadora. Su padre fue fumador $y$ sus tres hermanos también. Dos tíos suyos fumadores (hermanos del padre) habían muerto por cáncer de pulmón.

En el año 2008 dejó de fumar, y estuvo año y medio abstinente, recayendo en agosto de 2009. En el último año anterior a la evaluación realizada en 2011, no dejó de fumar, es decir, estuvo todo el 2010 fumando. El motivo que le indujo a dejar de fumar de aquella, igual que ahora, fueron motivos de salud y por miedo a las enfermedades que produce el tabaco. Es consciente de que fumar cigarrillos afecta gravemente a su salud y puede incrementar el riesgo de la aparición de un segundo tumor, así como una pérdida en su calidad de vida. Las molestias más importantes que le produce en la actualidad el tabaco son falta de aire, cansancio, taquicardias y dolores de cabeza.
Respecto al consumo de alcohol y café, toma un vaso de vino al día y un café a diario. En cuanto al consumo de fármacos, utiliza una pastilla para dormir desde hace 10 años, ya que padece insomnio. Esos problemas de insomnio aparecieron al mismo tiempo que el diagnóstico de su cáncer de pulmón.

Su deseo de dejar de fumar es muy alto, un 9 (en una escala de 0 a 10, donde 0 es nada y 10 lo máximo), y su deseo de realizar el tratamiento es de un 10. Sus expectativas acerca del tratamiento son muy positivas porque ya lo ha realizado en una ocasión anterior y consiguió dejar de fumar (en 2008, estando 18 meses abstinente).

En el Cuestionario de los estadios de cambio $^{(37)}$, M. C. C. se encuentra en el estadio de preparación para la acción, tiene la intención de dejar de fumar dentro de los próximos 30 días, y ha hecho intentos de al menos 24 horas sin fumar durante el último año.

Al hacer una comparación de las dos evaluaciones realizadas a M. C. C., la actual (2011) y la anterior (2008), observamos que se sitúa en el mismo estadio de cambio en las dos evaluaciones, en el estadio de preparación para la acción (hay que recordar que en estas dos ocasiones M. C. C. ya fue diagnosticado y operado de cáncer de pulmón).

Según los criterios de dependencia de la nicotina del DSM-IV-TR ${ }^{(38)}$ es dependiente de la nicotina ya que a menudo comprueba que cuando empieza a fumar acaba fumando más cigarrillos de los que tenía pensado; ha intentado controlar su consumo de tabaco o dejar de fumar; ha empleado mucho tiempo de su vida en fumar o haciendo lo necesario para conseguir tabaco; el consumo de tabaco le ha causado problemas psicológicos como sentirse ansioso, deprimido o le ha causado problemas para dormir, y había experimentado síntomas de abstinencia cuando 
interrumpía el consumo de tabaco. En el Test de Fagerström de Dependencia de la Nicotina $\left(\right.$ FTND) ${ }^{(39)}$ (en su validación española $\left.{ }^{(40)}\right)$, obtiene una puntuación de 3 , lo que indica una baja dependencia física; de hecho, tarda entre 31 y $60 \mathrm{mi}-$ nutos en fumar el primer cigarrillo del día; el cigarrillo al que odiaría más renunciar sería al primero de la mañana; $y$, fuma sobre todo durante las primeras horas después de despertarse. Su nivel de dependencia física de la nicotina, a través del Test de Fagerström de Dependencia de la Nicotina (FTND), en las dos ocasiones que acude a tratamiento $(2008,2011)$ es baja $(F T N D=3)$. Hay que recordar que acude después de haber sido operado de su cáncer de pulmón de hace años. En la Escala de Evaluación del Síndrome de Dependencia de la Nicotina (NDSS) ${ }^{(41)}$ (en su adaptación española ${ }^{(42)}$ ) obtuvo una puntuación de 34, lo que indica una dependencia alta.

Durante la entrevista indica que nunca ha tenido problemas psicológicos, aunque sí problemas físicos importantes. Desde hace 10 años, cuando le diagnosticaron el cáncer de pulmón y le extirparon el lóbulo superior derecho, tiene muchas dificultades para conciliar el sueño y para permanecer dormido, por ello toma desde esa fecha un ansiolítico para dormir. Relata que no puede estar sin esa pastilla porque si no "me ahogo, se me aprisiona el pecho y me quedo sin aire".

Para la evaluación de la psicopatología se administró el BDI-II ${ }^{(43)}$ (en su versión española ${ }^{(44)}$, para la evaluación de la sintomatología depresiva, dando una puntuación de 10, por lo que no presenta sospecha de sintomatología depresiva. Este mismo cuestionario se administra nuevamente en la última sesión de tratamiento y en los seguimientos de 1, 3, 6 y 12 meses para ver la evolución de la sintomatología depresiva. Se administró el Cuestionario de ansiedad estado-rasgo
(STAI A-E STAI A-R) ${ }^{(45)}$. En el STAI A-E, la puntuación directa es de 15, por lo que se sitúa en el centil 35; y en el STAI A-R es de 30, por lo que se sitúa en el centil 85. En el malestar percibido, evaluado a través del SCL-90- ${ }^{(46)}$, sus resultados se sitúan en la tabla de la población psiquiátrica, destacando fundamentalmente en las dimensiones de somatización, obsesión compulsión, sensibilidad interpersonal, depresión, ansiedad y psicoticismo. La comparación de las puntuaciones directas en el SCL-90-R con las puntuaciones del baremo de la población normal, en la primera y segunda ocasión que acude a este tratamiento para dejar de fumar pueden verse en la Figura 1 y 2.

En esta sesión de evaluación su nivel de monóxido de carbono ( $\mathrm{CO}$ ) en aire espirado, fue de 8 partículas por millón (ppm) a través del Micro IV Smokerlyzer (Bedfont Instruments, Sittingbourne, Kent, Reino Unido).

Durante la sesión de evaluación se le explicó a M. C. C. las características del tratamiento que iba a realizar para dejar de fumar. El objetivo de dicho tratamiento sería abordar la dependencia física, psicológica, y social del tabaco desde un tratamiento psicológico.

Una vez finalizada la evaluación acordamos un horario fijo a la semana para llevar a cabo el tratamiento. Se le proporcionaron autorregistros con el fin de conocer su conducta de fumar y se le indicó como cumplimentarlos (número de cigarriIlos fumados, hora en que los fuma, placer que le provocaba cada cigarrillo en una escala de 0 a 10 y situación en la que se encontraba). Dichos autorregistros debería de cumplimentarlos durante todos los días consecutivos hasta la primera sesión de tratamiento, con el fin de elaborar una línea base de consumo de cigarrillos pretratamiento.

El análisis funcional de la conducta de este caso se puede ver en la Tabla 1. 
Figura 1. Puntuaciones directas en el SCL-90-R y comparación con las puntuaciones del baremo de la población normal del cuestionario (año 2008, primera vez que acude a tratamiento).

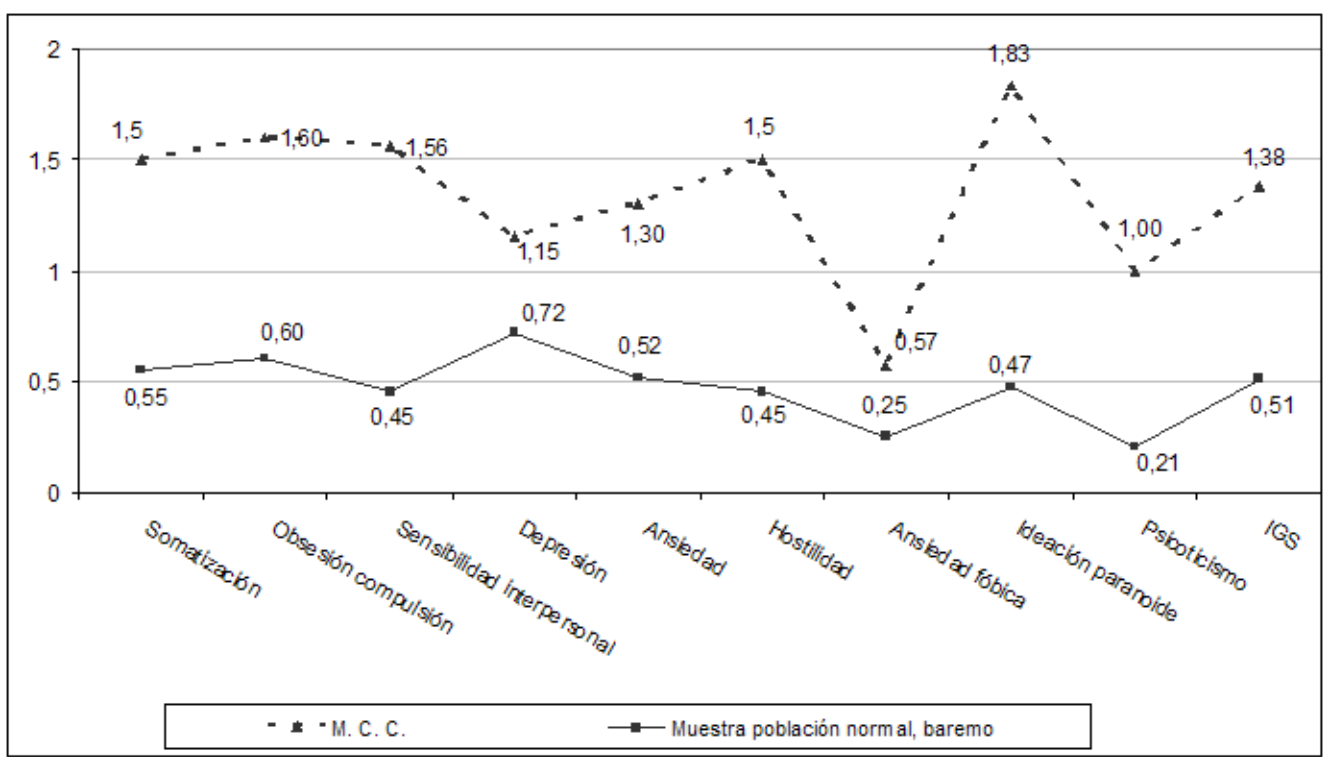

Figura 2. Puntuaciones directas en el SCL-90-R y comparación con las puntuaciones del baremo de la población normal del cuestionario (año 2011, última vez que acude a tratamiento).

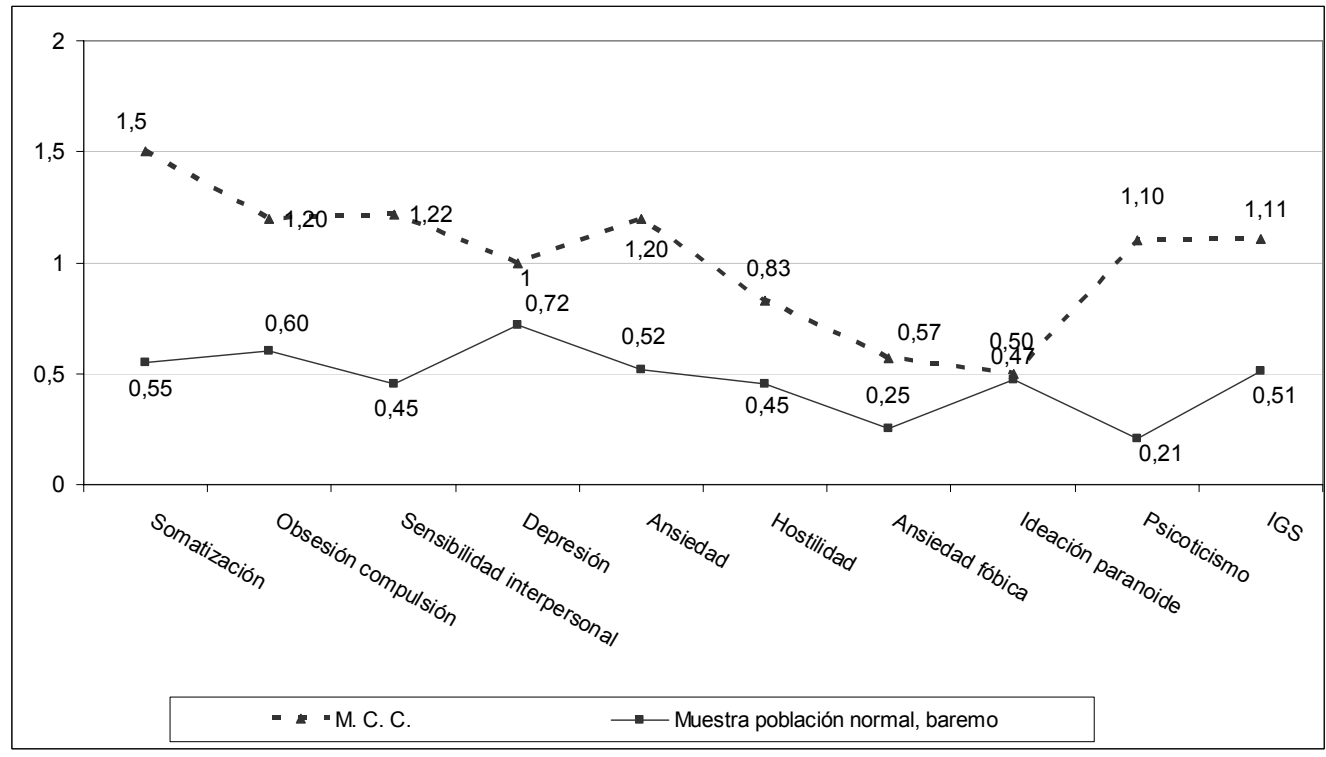




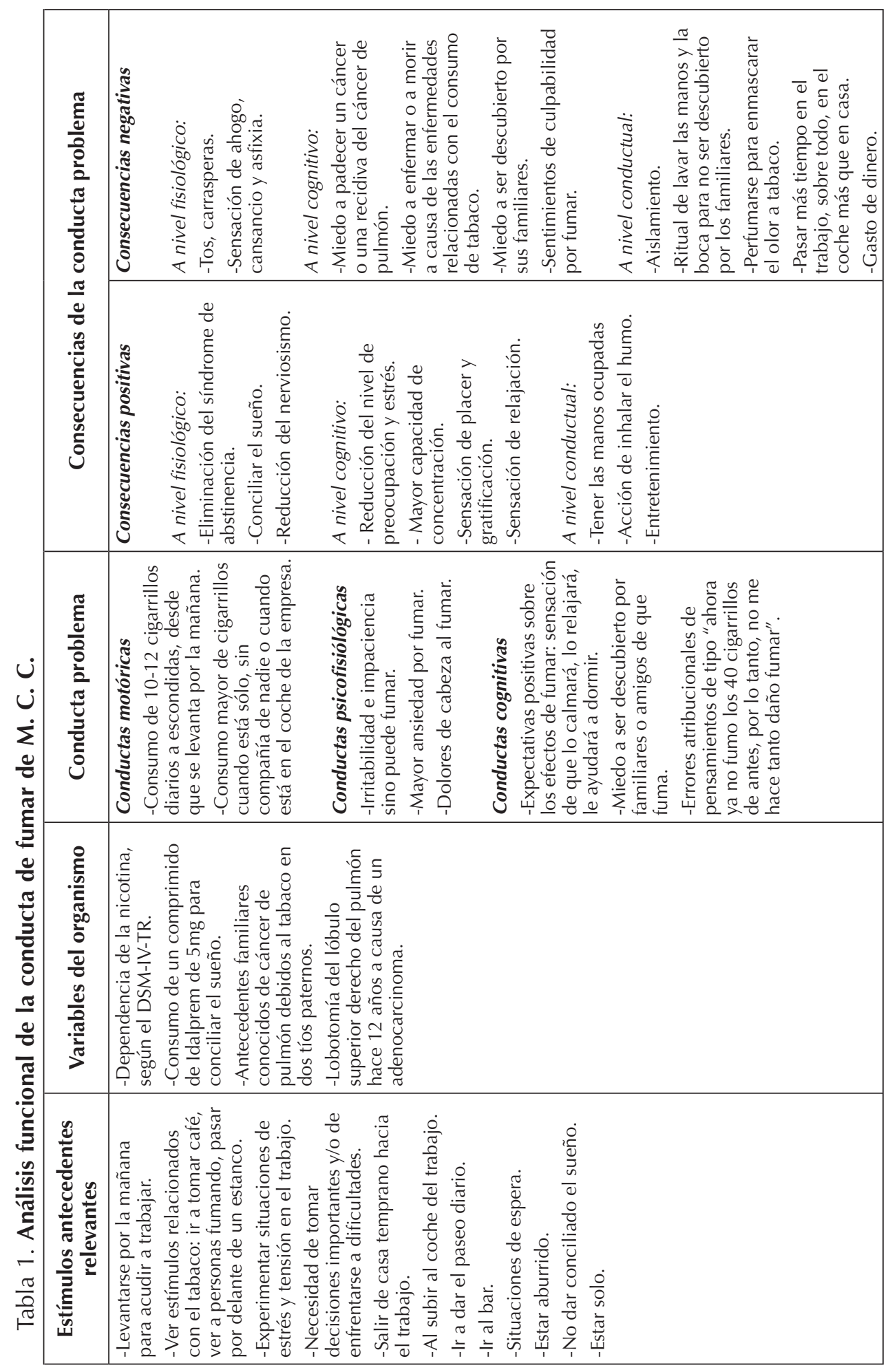




\section{Tratamiento}

Se le aplicó el Programa para Dejar de Fumar ${ }^{(47,48)}$, a lo largo de 6 sesiones de tratamiento, una por semana. Este tratamiento cognitivo-conductual consta de los siguientes elementos: contrato terapéutico de tratamiento, autorregistros y representación gráfica del consumo de cigarrillos, información general sobre el tabaco y los fumadores, reducción gradual de la ingesta de nicotina y alquitrán, control de estímulos, estrategias para no padecer el síndrome de abstinencia de la nicotina, feedback fisiológico del consumo de cigarrillos mediante medición de monóxido de carbono (CO) en aire espirado en cada sesión y estrategias de prevención de la recaída (entrenamiento en asertividad, solución de problemas, cambio de creencias erróneas, manejo de la ansiedad y de la ira, ejercicio físico, control del peso y autorreforzamiento) y de mantenimiento de la abstinencia.

Los porcentajes de abstinencia obtenidos con este tratamiento para dejar de fumar oscilan, en función de la muestra analizada, entre el $58 \%$ y el $85 \%$ al final del tratamiento, y el $30 \%$ y el $54 \%$ tras un año de seguimiento ${ }^{(49)}$. Sin embargo, en los últimos años ha habido una disminución de la eficacia de este tipo de tratamientos debido a que las personas que continúan fumando tienen una mayor dependencia de la nicotina, mayor psicopatología y el tratamiento se hace más complejo ${ }^{(50)}$.

\section{Primera sesión}

Al comienzo de la sesión se le entregó el material de las tareas a realizar durante la primera semana de tratamiento. Se realizó la medición de $\mathrm{CO}$ en aire espirado, dando un valor de 7 ppm (llevaba fumados dos cigarrillos, el último hacía 6 horas).

Se revisaron los autorregistros que realizó durante los días previos a la sesión, para establecer la línea base de consumo de cigarrillos pre-tratamiento, haciéndole ver a M. C. C. la importancia de los mismos y explicándole cómo representar el número de cigarrillos fumados diariamente, proporcionándole para ello una gráfica. A través de los autorregistros, se le explicó cuáles eran los antecedentes y consecuentes de su conducta de fumar. En su caso los antecedentes más importantes eran tomando café, conduciendo y paseando.

En esta primera sesión de tratamiento se le proporcionó información sobre los conceptos básicos del tabaco y de los fumadores y las consecuencias que produce en la salud. Se le solicitó que indicase las razones para dejar de fumar en estos momentos. Su razón fundamental para dejar de fumar era la salud (había tenido un adenocarcinoma en el pulmón derecho y, como consecuencia de ello, le habían extirpado el lóbulo superior derecho) aunque también, el no depender del tabaco. Indicó que cada vez que fuma se fatiga, se ahoga, se queda sin aire y le cuesta respirar y se angustia pensando que se va a morir, "cada cigarrillo que fumo me está quitando un poco de vida". Valora mucho su salud y ésta era su razón fundamental para dejar de fumar. Se comentó con él que la principal causa conocida de su cáncer de pulmón era el consumo de tabaco. Le explicamos que el volver a fumar podría hacer aparecer de nuevo un tumor en el pulmón, dado que al fumar tiene mayores posibilidades de una recidiva de cáncer. Por contra, sus razones para continuar fumando eran que le gustaba fumar y le relajaba cuando estaba tenso. Lo que se quiso comprobar al analizar los pros y los contras de fumar fue hacer ver a M. C. C. que actualmente tenía más razones para dejar de fumar que para seguir fumando.

Se le explicó a M. C. C. la necesidad de adoptar un papel activo y público en el abandono del tabaco. Para ello, se le pidió que comunicase a personas de su entorno que iba a dejar de fumar en los próximos 
30 días. Esto facilitaría la implicación activa de M. C. C. en el cambio de su conducta y poder analizar tanto las reacciones de esas personas como las suyas, ante la propuesta de dejar de fumar. M. C. C. dijo que no le podía contar a nadie que iba a dejar de fumar puesto que la gente que le rodea (familia, amigos, compañeros de trabajo) no saben que había vuelto a fumar desde que logró la abstinencia en el año 2008. Comenta que si se enteran su mujer y sus hijas se enfadarían mucho con él y las decepcionaría. Fuma a escondidas, "por eso fumo tan poco". Indica que le daría mucha vergüenza que se enterasen en su entorno que había vuelvo a fumar; incluso cuando va a las revisiones anuales por su cáncer, les miente a los médicos cuando le preguntan si había vuelto a fumar. Les dice que no fuma "aunque creo que saben que algo fumo" comenta.

Con la finalidad de ir disminuyendo el grado de dependencia fisiológica de la nicotina, se le cambió de marca de cigarrillos (a una marca con un 30\% menos de nicotina) y se le pautó un tope máximo de cigarrillos al día. Los cambios que se realizaron fueron los siguientes: como la semana antes de empezar el tratamiento M. C. C. fumaba una media de diez cigarrillos al día de la marca Winston Rojo de 0,8 mg de nicotina, se le pautó cambiar de marca de cigarrillos a otra más baja en nicotina, en este caso a Winston azul de 0,6 mg de nicotina y se le pautó un tope máximo de 6 cigarrillos diarios. M. C. C. podía fumar menos pero nunca superar ese tope. También se le recomendó comprar el tabaco siempre en el estanco, en vez de en las máquinas expendedoras de los bares y las cafeterías, puesto que las marcas que iba a fumar a lo largo del tratamiento no las encontraría en las máquinas expendedoras de tabaco. Se le explicó que esta pauta le ayudaría a ir rompiendo la asociación que tienen muchos fumadores (él también) de ir al bar y comprar tabaco. Así, también
Ilevaría un autocontrol y una planificación de la compra del tabaco.

Para esta primera semana se le proporcionaron cuatro reglas que debía poner en práctica para evitar la compensación nicotínica, como fumar un tercio menos del cigarrillo, ya que lo fumaba entero hasta el filtro; no aceptar ofrecimientos de otros cigarrillos, con el objetivo de que adquiriera un papel activo al rechazar ofrecimientos y al decir que está dejando de fumar y que solamente puede fumar de su tabaco. Esta regla le resultó muy fácil de aplicar puesto que nadie sabía que fumaba; reducir la profundidad de la inhalación; y, llevar el cigarrillo a la boca sólo para fumarlo.

Antes de finalizar la sesión, se realizó un resumen de toda la sesión y se le preguntó si tenía alguna duda o necesitaba alguna aclaración de algún aspecto y se quedó con él para la siguiente semana.

\section{Segunda sesión}

Al comienzo de la segunda sesión se le entregó el material de la sesión y se midió el CO. Su nivel de CO en esta sesión fue de 6 ppm, (llevaba fumados tres cigarrillos, el último hacía 5 horas y 30 minutos).

Se le preguntó por cómo llevó las normas y las pautas dadas en la sesión anterior. M. C. C. había respetado el tope máximo acordado (seis cigarrillos diarios), habiendo fumado incluso menos, cuatro y cinco cigarrillos al día. Se le reforzó por ello y revisamos el modo en el que había aplicado las reglas prácticas proporcionadas para reducir el consumo de cigarriIlos. En general, no tuvo problemas con las pautas. Lo único que comentó fue que el tabaco que fumó durante la semana pasada no le supo nada, le sabía muy flojo, "es como fumar paja". Se le dijo que podría ser cierto que los primeros días no le supiese bien, pero que con el paso de los días acabaría por acostumbrarse. Además, se le dijo que el que no supiese bien el ta- 
baco era una razón a su favor para reducir antes el consumo.

Esta semana, se volvió a realizar un cambio de marca y a pautar un número máximo de cigarrillos, con el objetivo de ir perdiendo la dependencia fisiológica de la nicotina. La nueva marca que tendría que fumar sería Gold Coast Blanco con 0,4 mg de nicotina, lo que supondría una reducción del $60 \%$ respecto a la que fumaba al comienzo del tratamiento y un $30 \%$ menos con respecto a la semana pasada. El número máximo de cigarrillos que podría fumar al día durante toda la semana sería de 4 cigarrillos diarios y todos ellos por la mitad.

Analizamos conjuntamente los autorregistros, prestando especial atención a los antecedentes y consecuentes y se le entrenó en la técnica del control estimular. Para ello, tenía que elegir al menos tres situaciones (las que le resultasen más fáciles) en las que a partir del día siguiente dejaría de fumar para siempre. Esto se hizo presentándole un grupo de situaciones que suelen abarcar casi todos los posibles estados en los que un fumador normal fuma. M. C. C. tenía muy pocas situaciones en las cuales fumaba, fundamentalmente fumaba con el café, conduciendo la furgoneta de la empresa y paseando. Eligió como situaciones a eliminar fumar en la calle y conduciendo el coche, y prefirió seguir fumando con el café. Le explicamos cómo debería de proceder en la situación de conduciendo el coche: antes de subir al coche debería de guardar la cajetilla en el maletero. Si le apeteciese fumar tendría que parar, bajar del coche, abrir el maletero y fumar, y después esperar 15 minutos para volver a subir al coche. En la situación de paseando no podría llevar el tabaco encima cuando saliera a pasear, o lo fumaba antes, sentado, o de pie, quieto, o sino lo fumaría 30 minutos como mínimo después del paseo de pie o sentado.

También se le proporcionaron una serie de estrategias para no padecer el síndrome de abstinencia de la nicotina, como beber abundante agua, reducir el consumo de alcohol y de café, realizar ejercicio físico, masticar chicles o caramelos sin azúcar, etc. Por si esto no fuera suficiente, se le explicó la técnica de respiración profunda para que la pusiese en práctica varias veces al día a lo largo de toda la semana.

Por último, se hizo un repaso de todo lo expuesto, se le preguntó si tenía alguna duda y se concertó la cita para la siguiente sesión.

\section{Tercera sesión}

Al comienzo de la sesión se le entregó el material y se tomó la medida de CO. M. C. C. puntuó 0 ppm, Ilevaba 2 días abstinente. Se le reforzó por la abstinencia conseguida y se le animó a seguir así. Se le preguntó por las sensaciones que notaba al estar sin fumar. Nota que respirar mejor, que no se ahoga, ni se fatiga tanto.

Es de destacar que siguiendo este tratamiento lo habitual es que la mayoría de los fumadores alcancen la abstinencia en la cuarta o quinta sesión. M. C. C. lo dejó antes porque estaba muy motivado para dejar de fumar y tenía unas razones de salud muy poderosas para abandonar el tabaco.

Se le comentó que en esta semana era habitual empezar a experimentar mejoría física, a la vez que una mejor percepción de los olores y sabores. M. C. C, comentó que las comidas le sabían algo mejor y que no se fatigaba tanto, pero que notaba cierta tos y picor en la garganta y que estaba durmiendo regular. Se le explicó que ello puede ser debido al fenómeno de regeneración corporal (incremento de la tos, carrasperas, mocos...), porque se están eliminando las sustancias nocivas de su cuerpo (por ejemplo, el alquitrán).

Preguntando sobre cómo realizó el abandono, indica que estuvo toda la sema- 
na fumando cuatro cigarrillos por la mitad y que planificó el abandono cuando acabó la cajetilla "el día que acabe esta cajetilla ya no fumo más". Se le animó a mantener la abstinencia para la siguiente sesión y se le pidió que se fijase en las mejorías que experimentaría al estar sin fumar.

Sobre las situaciones acordadas en la semana anterior para no fumar, indica que gracias a ellas dio el paso para dejar de fumar ya que no tenía donde fumar. En casa no fumaba porque no sabían que había vuelto a fumar, en el trabajo tampoco y sólo fumaba en un bar donde no sabían de su problema físico y en el coche o cuando iba a dar su paseo diario.

En cuanto a las estrategias para no padecer el síndrome de abstinencia de la nicotina comentó que las que mejor le funcionaron fueron los chicles y caramelos, beber agua y la respiración profunda. Se le animó a que aplicara las mismas estrategias que le habían ayudado a eliminar algún consumo en la semana anterior, para que esta semana se mantuviese abstinente.

Llevar 2 días abstinente supone para él un alivio, "es como si me quitasen un peso de la cabeza", porque dice que cada vez que quería fumar un cigarrillo tenía que pensar dónde fumarlo, cuándo, para que nadie le viese y después de fumarlo siempre hacía el ritual de lavar la boca, o mascar un chicle de menta o caramelos, y se perfumaba. Está contento porque ya respira mejor, pero tiene miedo a no dar dormido por las noches. Incluso tomando la pastilla para dormir estos días que lleva abstinente está notando que tiene dificultades para dormir. Le decimos que eso es pasajero, que incluso va a dormir y a descansar mucho mejor sin nicotina en el cuerpo.

Al final de esta sesión se introdujo el tema del control del peso. M. C. C. comentó que no le preocupaba en absoluto puesto que ya seguía un régimen por "prescripción de su mujer" donde no tomaba ni sal, ni fritos y tomaba mucha fruta y verdura además de caminar 1 hora diaria.

Se finalizó la sesión con un resumen y preguntándole por alguna duda. Se programó una cita para la próxima semana.

\section{Cuarta sesión}

Una semana después, M. C. C. siguió manteniéndose abstinente. Su CO fue de 3 ppm y llevaba 9 días sin fumar. Refirió encontrarse mejor incluso que la semana pasada. Esto confirmó su idea de que había tomado la decisión correcta al dejar de fumar. Se reforzaron los logros alcanzados (mejoría física, mejoría en los sabores y olores, sensación de libertad).

Se le preguntó si se le había presentado algún problema a lo largo de la semana. Destacó que había tenido insomnio y problemas con el patrón del sueño a pesar de estar tomando una pastilla para dormir. Además, comenta un hecho que le resultó curioso, como "una prueba de fuego". Yendo a dar su paseo habitual de 1 hora se encontró en el suelo una cajetilla de cigarrillos de la marca que él fumaba (Winston Rojo) sin empezar y cerrada. Le entraron unas ganas enormes de abrirla y fumar, pero no lo hizo. La cogió, la metió en el bolsillo y la tiró en un contenedor. Se sintió muy orgulloso de no haber fumado y se le reforzó ese hecho. M. C. C. comentó que en otra época quizás hubiese abierto la cajetilla y se la hubiese fumado. Medio en broma comentó "me están poniendo a prueba a ver si aguanto sin fumar". Se le dijo que ese había sido un hecho fortuito y se le refuerza su comportamiento indicándole que le ganó la batalla al tabaco, que ahora era más fuerte y que iba a ganar mucho en términos de salud.

Retomando algunos acontecimientos sucedidos en sesiones anteriores, se introdujo la técnica de solución de problemas, como una herramienta clave para la toma 
de decisiones ante situaciones difíciles. Por ello, tras indicarle en qué consistía se le sugirió que utilizase esta técnica ante cualquier problema, como el que le había surgido días atrás (encontrarse una cajetilla de cigarrillos).

Dado que M. C. C. había intentado dejar de fumar antes de acudir al tratamiento, se analizaron cuáles habían sido las principales causas de la recaída en aquel momento: la falsa percepción de control y para calmar la ansiedad y afrontar el estrés. Al igual que muchos fumadores, la creencia de que "por fumar un cigarrillo no pasa nada" y el creer que el fumar alivia la ansiedad y el estrés, le animaban a confirmar esta creencia. Esas creencias le habían Ilevado a recaer en el pasado tras 18 meses de abstinencia. Por ello se introdujo, en primer lugar, la distinción entre caída y recaída y le explicamos en que consistían una y otra. Le pedimos que reflexionase sobre estas cuestiones para comentarlas en la siguiente sesión.

Se hizo, además, un análisis de las tentaciones o impulsos a fumar que podían surgirle como no fumador en las primeras semanas. Aunque a lo largo del tratamiento el impulso o la necesidad de coger un cigarrillo había disminuido en frecuencia e intensidad, M. C. C. tenía miedo de no ser capaz de afrontarlos eficazmente. Le recomendamos que detectase cuáles podían ser las situaciones en las que tuviese un mayor craving (ej., tomar el café, ir a dar el paseo, conducir...) y que tuviese varias estrategias útiles para hacer frente a esas situaciones. Pensar que ese impulso sólo duraría unos segundos y luego desaparecería, junto a analizar los motivos por los que había decidido abandonar el tabaco, sería lo mejor que podía hacer para controlar los deseos de fumar.

Finalmente, se hizo un resumen de la sesión y se quedó con él para la sesión de la próxima semana.

\section{Quinta sesión}

Como en las sesiones anteriores, al comienzo de cada sesión se le entregó el material. Su nivel de $\mathrm{CO}$ fue de 2 ppm. Llevaba 16 días in fumar.

Le preguntamos por cómo se encuentraba y nos comenta que mejoró en muchos aspectos, tanto físicos como psicológicos, ya que a nivel físico es capaz de salir a caminar más tiempo y no llega tan fatigado como antes. Y a nivel psicológico se siente con más control, con más ganas de hacer cosas, "me siento más vital".

Se comentaron algunas sensaciones que podría notar al estar sin fumar, como tener la sensación de que le falta algo, ganas de fumar, sequedad de boca, sabor a nicotina en la boca, estreñimiento, etc. $M$. C. C. comentó que notaba que al pasear los bolsillos le pesaban menos porque no llevaba la cajetilla. Además, que el dinero le duraba más puesto que dejó de ir al bar donde tomaba el café por la mañana con el cigarrillo.

Se analizaron distintas creencias erróneas que con frecuencia suelen llevar a los exfumadores a la recaída como por ejemplo, que al dejar de fumar, uno se vuelve más nervioso o ansioso, irascible o agresivo, se gana peso, se pierde la concentración, si se fuma un cigarrillo ya se vuelve a recaer, etc.

Le pedimos que reflexionara durante la semana sobre su situación actual y sobre cómo le gustaría que discurrieran las cosas a partir de ahora (incluido el tema de dejar de fumar).

Para finalizar, hicimos un resumen de la sesión y se quedó con él para la siguiente sesión de la próxima semana.

\section{Sexta sesión}

M. C. C. acude sin fumar. Lleva 23 días sin fumar y su nivel de CO fue de 2 ppm. Para él estar sin fumar es un logro muy 
importante, pero le asusta recaer, porque ya sabe lo que es dejar de fumar y volver de nuevo a fumar.

En esta sesión se dedicó un apartado especial a hablar de las consecuencias positivas que experimentó al dejar de fumar y de cómo se ve en el futuro sin fumar. Comenta que el abandono del tabaco le resultó mucho más fácil de lo que esperaba al acudir a tratamiento, está muy contento y ni se acuerda del tabaco en su día a día. En cuanto a las mejorías físicas experimentadas indicó que respira mejor, que apenas nota cansancio y que está experimentando una gran sensación de libertad. Además, indicó que a nivel psicológico, su autoestima aumentó, ahora se siente capaz de todo y está muy orgulloso de sí mismo. Dice que ganó en calidad de vida, ya que simplemente, librarse de la sensación de ahogo significa para él quitarse un gran peso de encima.

Comenta que tenía un motivo muy importante para dejar de fumar, su salud. Es consciente de que si volviese a fumar podría desarrollar otro cáncer de pulmón. Si fumase de nuevo es consciente de que su calidad de vida se empobrecería ya que se cansaría y se fatigaría al hacer cosas y entonces, preferiría no hacerlas.

Al final del tratamiento, M. C. C. completó el cuestionario de evaluación de final del tratamiento (estatus de fumador en ese momento, apoyo social que ha recibido durante el proceso de abandono, mejorías físicas y psicológicas que ha experimentado tras dejar de fumar, síntomas de la abstinencia del tabaco, etc.). M. C. C. afirmaba no haber recibido apoyo de las personas que le rodean para dejar de fumar puesto que nadie sabía que había vuelto a fumar. Su confianza en mantenerse sin fumar en los próximos 6 meses fue de 5 (en una escala de 0 a 10). A pesar de los resultados del tratamiento su confianza es baja.

\section{Seguimientos}

Se realizaron seguimientos presenciales al mes, 3, 6 y 12 meses después de haber finalizado el tratamiento ${ }^{(51)}$ y se validó la abstinencia autoinformada mediante la evaluación de monóxido de carbono en aire espirado $^{(52)}$. M. C. C. acudió abstinente a todos los seguimientos.

El seguimiento, ya sea mediante contacto personal, por carta o mediante conversaciones telefónicas, aumenta significativamente los índices de éxito en los fumadores que realizan un tratamiento para dejar de fumar ${ }^{(49)}$.

En el seguimiento de 1 mes, M. C. C. se mantiene abstinente. Su nivel de $\mathrm{CO}$ fue de 2 ppm. A veces le surgieron tentaciones o impulsos a fumar, sobre todo cuando volvió a ir al bar a tomar café y cuando veía a gente fumar, pero dice que es capaz de controlarlas fácilmente cambiando el pensamiento y cambiando de actividad. Está muy contento por las mejorías experimentadas (respirar mejor, no se ahoga, tiene menos cansancio y, sobre todo, por la sensación de libertad y de liberación tan grande que siente). En este seguimiento su confianza en mantenerse sin fumar en los próximos 6 meses fue de 10 (en una escala de 0 a 10) y en los próximos 12 meses de 8. Es de destacar que aumentó considerablemente su confianza en mantenerse sin fumar con respecto a la puntuación de final del tratamiento, pasando de 5 a 10 . Al preguntarle el porqué de ese aumento dice que "me encuentro bien cuando no fumo". Relata que su calidad de vida es mucho mejor sin el tabaco porque no experimenta la sensación de asfixia, de morir ahogado. Para M. C. C. ser un exfumador representaba muchas mejorías en la salud y libertad.

En el seguimiento de 3 meses, M. C. C. sigue manteniendo su abstinencia, su nivel de CO fue de 3 ppm. Se le volvió a preguntar por las ventajas que veía en mantenerse sin fumar indicando que tenía claras me- 
Figura 3. Evolución del consumo de tabaco (número de cigarrillos/día) y monóxido de carbono (CO) a lo largo del tratamiento y seguimientos (año 2008, primera vez que acude a tratamiento).

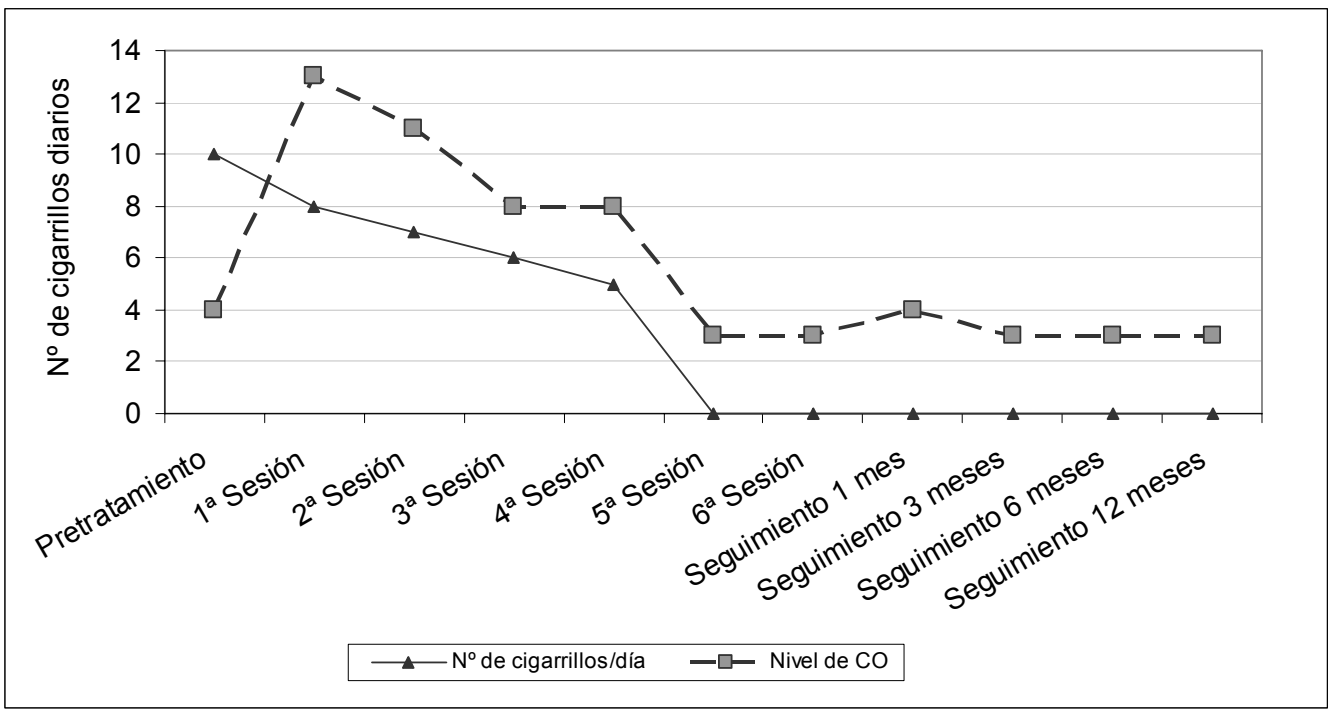

Figura 4. Evolución del consumo de tabaco (número de cigarrillos/día) y monóxido de carbono ( $\mathrm{CO}$ ) a lo largo del tratamiento y seguimientos (año 2011 , última vez que acude a tratamiento).

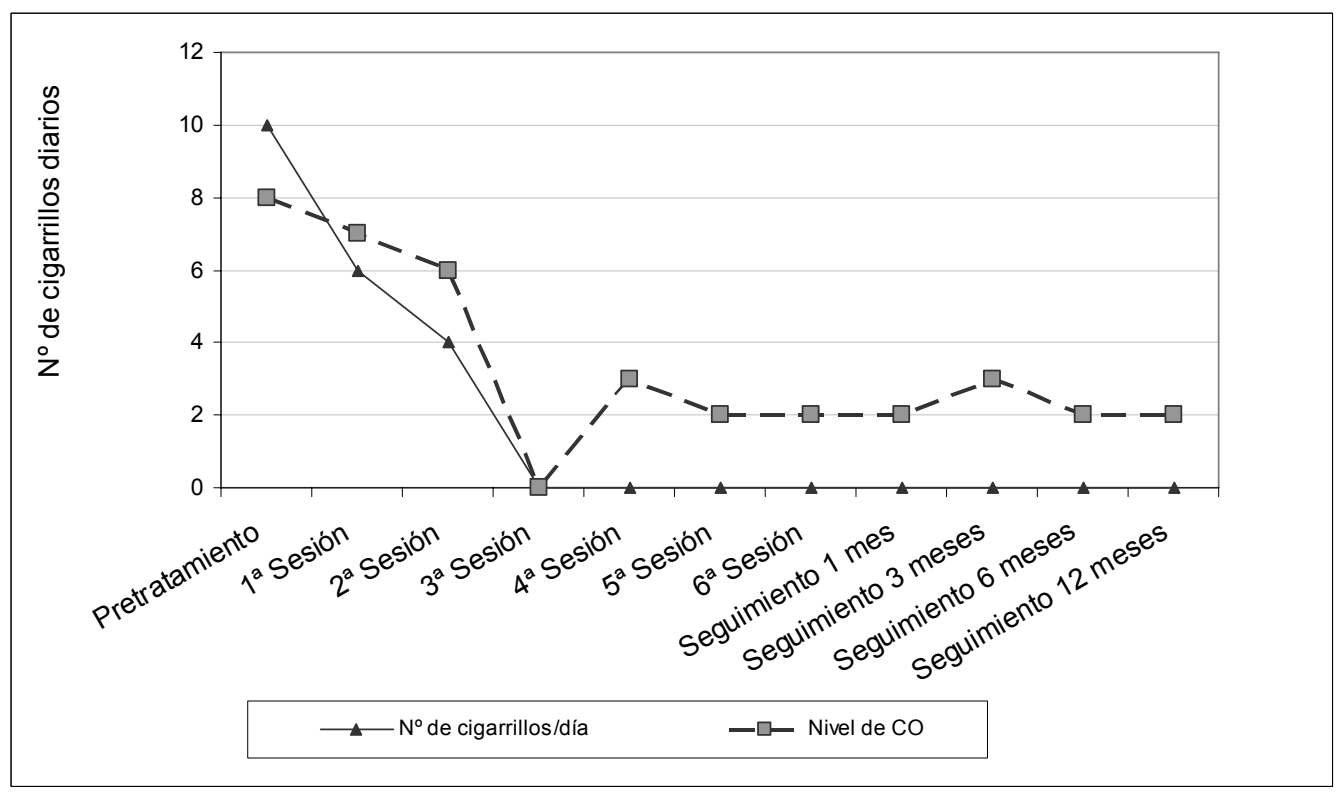


jorías en la salud, el no depender de una sustancia y otra más que no había contemplado anteriormente: las ventajas económicas que tiene el no fumar. Ahora el dinero le cunde más y, a pesar de que él fumaba sobre 10 cigarrillos al día, llevaba ahorrados desde que dejó de fumar 180 euros. En este seguimiento su confianza en mantenerse sin fumar en los próximos 6 meses fue de 10 y, para los próximos 12 meses, de 9 . En este seguimiento, M. C. C. nos comenta que la semana anterior fue a su revisión anual con su oncólogo para ver cómo iban sus pulmones. Le indicaron que todo iba muy bien, sin ningún dato nuevo ni síntoma raro. Las revisiones oncológicas las tiene anuales. Acude a ellas con mucho miedo de que le descubran algo. Lo que peor lleva son las pruebas de capacidad pulmonar ya que desde la operación (extirpación en el año 2000 del lóbulo superior derecho de su pulmón) no consiguió aumentar nada su capacidad pulmonar. M. C. C. lo achaca a volver a fumar y a no seguir realizando los ejercicios que le habían recomendado de rehabilitación respiratoria.

En el seguimiento de 6 meses, M. C. C. acude abstinente, su nivel de $\mathrm{CO}$ fue de 2 ppm. Se encuentra igual de bien que en el último seguimiento. Respira muy bien y ya no se cansa tanto. A pesar de ello comenta que, a veces, sobre todo en días malos en el trabajo, se acuerda del tabaco, aunque cambiando de actividad o pensando en otra cosa se le olvida fácilmente. El sueño le va mucho mejor, incluso está dejando de tomar la pastilla para dormir pautada por el psiquiatra y no le está costando nada. En este seguimiento su confianza en mantenerse sin fumar en los próximos 6 meses fue de 10. Y para los próximos 12 meses de 9 .

En el seguimiento de los 12 meses, $\mathrm{M}$. C. C. sigue sin fumar, su nivel de CO fue de $2 \mathrm{ppm}$. A pesar de ello, M. C. C. comenta que en el mes de septiembre (dos meses antes del seguimiento de los 12 meses) fumó tres cigarrillos un día. Al preguntarle por cómo ocurrió nos cuenta que fue a raíz de problemas en el trabajo. La compañía para la que trabaja iba a realizar un expediente de regulación de empleo (ERE) y tenía que tomar una decisión importante, prejubilarse cobrando una indemnización, o adaptarse a las nuevas condiciones que le impusiesen si se quedaba en la empresa. Tras muchos días de tensión decidió ir a comprar cigarrillos. Al preguntarle por cómo se sintió en el momento de coger y fumar ese primer cigarrillo, comenta que se sintió asustado, inquieto y derrotado. Se mareó y le supo mal. No había pensado en la posibilidad de recaer. Después de fumar esos cigarrillos se sintió culpable, enfadado y con una sensación de fracaso muy grande. Por una parte se sintió fracasado, pero por otra parte se sintió muy bien, muy orgulloso de sí mismo puesto que cogió la cajetilla de tabaco y la pisoteó y la tiró diciendo "tú no vas a poder conmigo". Comenta que se acordó de lo hablado a lo largo del tratamiento cuando le enseñamos "el entrenamiento en solución de problemas". Cuando recordó esto se dio cuenta de que fumar no era la solución al problema laboral y que si no ponía remedio volvería a tener dos problemas, el laboral y el volver a ser de nuevo fumador. Le felicitamos por la adecuada decisión tomada y le reforzamos el haber puesto en funcionamiento todo lo aprendido a lo largo del tratamiento. En este seguimiento su confianza en mantenerse sin fumar en los próximos 6 meses fue de 10 y en los próximos 12 meses también 10 .

La evolución de su consumo de cigarriIlos y su nivel de CO se pueden ver en las Figura 3 (tratamiento de 2008) y Figura 4 (tratamiento actual).

\section{DISCUSIÓN}

La principal causa conocida del cáncer de pulmón es el consumo de tabaco, que es el responsable de más del $90 \%$ de los casos de cáncer de pulmón ${ }^{(9-11)}$. Al tratar 
a pacientes fumadores diagnosticados de cáncer de pulmón les explicamos que su cáncer se debe y se agudiza por el consumo de tabaco, consiguiendo mejorar en la enfermedad y en la calidad de vida al dejar de fumar ${ }^{(29)}$. Dejar de fumar, en estos pacientes, tiene efectos positivos muy significativos, como la disminución del riesgo de la enfermedad, el aumento del tiempo de supervivencia, la disminución de las complicaciones quirúrgicas y del postoperatorio, la reducción de las complicaciones de la radioterapia, una mayor tolerancia y resistencia al ejercicio y una mejora significativa de la calidad de vida, incrementando los niveles de actividad y movilidad $^{(29,30,31,32,33,34)}$.

El riesgo de desarrollar cáncer de pulmón es más común entre los fumadores y el riesgo lo determina el número de cigarrillos consumidos diariamente y los años que Ileva la persona fumando ${ }^{(9)}$. En nuestro caso, M. C. C. había comenzado a fumar a los 13 años y a pesar de que comenzó fumando pocos cigarrillos al día (tres cigarrillos diarios sin filtro) pronto alcanzó los 40 cigarrillos diarios durante casi 20 años (desde los 24 años hasta los 42 que le detectaron el cáncer de pulmón).

En este caso, la detección temprana del cáncer fue un factor muy favorable para tener un mejor pronóstico de la enfermedad. Debido a que los síntomas del cáncer de pulmón a menudo no se manifiestan hasta que la enfermedad está avanzada, sólo un pequeño porcentaje se detecta en las etapas iniciales ${ }^{(23)}$. Muchos casos de cáncer de pulmón en etapa temprana se diagnostican accidentalmente, lo que significa que se detectan como resultado de pruebas médicas que se llevan a cabo debido a otro problema de salud no relacionado. En nuestro caso, a M. C. C. se le detectó su cáncer en un estadio muy temprano (estadio I) descubierto de forma fortuita al haber acudido al médico de atención primaria por un dolor muscular.
M. C. C. acudió en dos ocasiones a este mismo tratamiento para dejar de fumar, una, en el año 2008, y la segunda, en el año 2011, consiguiendo la abstinencia en las dos ocasiones. En esta última ocasión (año 2011), después de realizar el tratamiento psicológico para dejar de fumar de seis sesiones, M. C. C., que fumaba una media de 10 cigarrillos diarios de la marca Winston Rojo (0,8 mg. de nicotina) en el momento de la evaluación, dejó de fumar en la tercera sesión. Luego se mantuvo abstinente en todos los seguimientos realizados (1, 3, 6 y 12 meses). Sabemos que fumar pocos cigarrillos antes del tratamiento, tener un nivel bajo de dependencia de la nicotina y haber hecho intentos de abandono en el pasado, están asociados con altas tasas de abstinencia ${ }^{(53,54)}$.

Su motivación para realizar el tratamiento para dejar de fumar fue muy alta en las dos ocasiones (10, el nivel máximo). El motivo por el que acude a dejar de fumar tanto en esta última ocasión como la vez anterior fue por motivos de salud $y$ por miedo a las enfermedades que causa el tabaco. De hecho, en varias ocasiones relata su miedo a morir por quedarse asfixiado y ahogado por no dar respirado a causa de fumar.

Acudió dos veces a dejar de fumar (la primera en el 2008 y la segunda en el 2011) y en las dos alcanza la abstinencia aunque recae en la primera ocasión después de lograr mantenerse 18 meses abstinente. Sabemos que el abandono del consumo de tabaco es un proceso dinámico que suele implicar una secuencia de intentos fallidos antes de lograr una abstinencia continua en el tiempo ${ }^{(55)}$. Dejar de fumar es un proceso que puede llevar varios años a una persona. Cuantas más ayudas se le proporcionen al fumador, mayores serán las probabilidades para finalmente dejar de fumar ${ }^{(56)}$.

El apoyo recibido de las personas que le rodean para dejar de fumar fue escaso 
puesto que las personas de su entorno no sabían que había vuelto a fumar, por lo tanto no podían apoyarlo en el abandono.

M. C. C. no tuvo grandes dificultades para abandonar el consumo de cigarrillos ni para mantenerse abstinente debido sobre todo a las mejorías experimentadas en la salud y el aumento en su calidad de vida. Se situaba en el estadio de cambio de "preparación para la acción" y su nivel de dependencia física del tabaco era baja (FTND igual a 3). Estas dos variables (situarse en el estadio de cambio de preparación para la acción y tener una puntuación baja en el FTND) fueron asociadas con la abstinencia a largo plazo $^{(57)}$. Se había propuesto firmemente el abandono y su planificación en un futuro cercano. El hecho de encontrarse mal físicamente (con falta de aire, fatiga, sensación de ahogo y haber tenido una extirpación del pulmón a causa de un adenocarcinoma) desempeñó un papel decisivo para que M. C. C. dejase de fumar y se mantuviese abstinente.

Al finalizar el tratamiento, su confianza en mantenerse sin fumar en los próximos 6 meses fue de 5 (en una escala de 0 a 10). Vemos que no confiaba mucho en sí mismo para mantenerse abstinente. Esto puede ser debido a que la primera vez que realizó este tratamiento también alcanzó la abstinencia pero después recayó al año y medio. Sin embargo, observamos como al analizar los seguimientos, su confianza en mantenerse abstinente va en aumento, pasando de 5 a 10. Observamos, por lo tanto, que su confianza fue en aumento sobre todo gracias a las mejorías físicas experimentadas y al aumento de su calidad de vida relacionada con la salud.

Por lo que respecta a su evolución a lo largo del tratamiento, M. C. C. cumplió el tope de cigarrillos indicado en cada sesión, así como la realización de todas las tareas encomendadas, no observándose especial dificultad en su realización, cumpliendo todas ellas. En cuanto a la adherencia al tratamiento y al seguimiento acudió a todas las sesiones y en el horario establecido, lo cual es un aspecto que facilita el mantenimiento de la abstinencia, tanto a corto plazo ${ }^{(58)}$, como a largo plazo ${ }^{(59)}$.

M. C. C. indica que la principal molestia de dejar de fumar o el principal inconveniente al dejar de fumar fue el tema del sueño, el cual ya estaba de por sí alterado desde el diagnostico de cáncer. Al dejar de fumar tuvo algunos días de insomnio y de despertar a media noche, aunque pronto volvió a recuperar el patrón de sueño normal. Sólo le ocurrió unos días.

El seguimiento nos permitió detectar la existencia de complicaciones durante el periodo de abstinencia. Durante este periodo pudimos indagar en las debilidades que sentía a lo largo del tiempo con respecto del tabaco y nos ayudó a corregir cualquier circunstancia que dificultase la abstinencia. Al igual que en el tratamiento, en los seguimientos acudió a todas las sesiones y cumpliendo estrictamente el horario establecido por el terapeuta. En el seguimiento pudimos apreciar claramente como un cambio laboral o una situación difícil a nivel laboral Ilega a producir un estado emocional negativo que es muy difícil para un ex-fumador afrontarlo sin sus cigarrillos. De hecho, los estados emocionales negativos son los que más contribuyen a que una persona recaiga y vuelva a fumar ${ }^{(60,61)}$. Además, síntomas de depresión y de ansiedad fueron identificados como disparadores de la recaída en el tabaco en pacientes con cáncer de pulmón ${ }^{(62)}$. Aún así, M. C. C. puso todo su empeño para recuperar su abstinencia ya que los efectos beneficiosos de dejar de fumar fueron muy grandes en su caso puesto que se encontraba con más energía, menos fatigado y con mejor gusto y olfato.

A lo largo de los seguimientos pudimos comprobar como M. C. C. sentía miedo e incertidumbre cada vez que acudía a su revisión rutinaria de oncología. Tenía mie- 
do a la recurrencia o recidiva del cáncer de pulmón, motivo fundamental por el que acude a tratamiento para dejar de fumar en dos ocasiones, a pesar de que en los seguimientos rutinarios a la consulta de oncología le dijesen que todo estaba bien. Miedo y grados importantes de incertidumbre son sensaciones que experimentan los pacientes con cáncer de pulmón, aunque el tratamiento quirúrgico en etapas tempranas sea considerado curativo ${ }^{(63)}$.

En vista de los resultados obtenidos, este caso pone de relieve los efectos beneficiosos de dejar de fumar en pacientes que han sufrido cáncer de pulmón y que tienen la función pulmonar disminuida. La continuidad en el consumo de tabaco en personas que han sufrido cáncer puede reducir su supervivencia, incrementar el riesgo de la aparición de un segundo tumor y/o disminuir la efectividad del tratamiento médico para ese cáncer, así como una pérdida en la calidad de vida ${ }^{(31)}$.

El tratamiento psicológico para dejar de fumar, el "Programa para Dejar de Fumar" (47,48), que aquí se utiliza, ha demostrado ser adecuado para el abordaje del presente caso. El mismo ha sido exitoso no sólo al finalizar el tratamiento sino que los resultados se han mantenido a lo largo del seguimiento de un año. Existe evidencia empírica suficiente que avala la eficacia de los tratamientos psicológicos para dejar de fumar ${ }^{(64,65)}$.

En conclusión, dejar de fumar es la medida más simple que puede hacer cualquier persona fumadora para mejorar su salud ya que, al dejar de fumar, se mejora en muchos aspectos, aumenta la calidad de vida y se gana en bienestar físico y mental.

\section{REFERENCIAS BIBLIOGRÁFICAS}

1. Becoña E. Tabaco. Prevención y tratamiento. Madrid: Pirámide, 2006.

2. Alonso JM. Tabaco y cáncer. En: Becoña
E, editor. Libro blanco de prevención del tabaquismo. Barcelona: Glosa Ediciones; 1998.p.57-78.

3. Vineis $\mathrm{P}$, Alavanja $\mathrm{M}$, Buffler $\mathrm{P}$, Fontham $\mathrm{E}$, Franceschi S, Gao YT, et al. Tobacco and cancer: Recent epidemiological evidence. J Natl Cancer Inst 2004;21; 96:99-106. Doi: 10.1093/jnci/djh014.

4. Ruíz JJ. Consumo de tabaco y patología tumoral. En: Jiménez CA, Fagerström KO, editores. Tratado de tabaquismo. Madrid: Ergon, 2007. p. 149-154.

5. U.S. Department of Health and Human Services. The Health Consequences of Smoking: A report of the Surgeon General. Atlanta (GA): U.S. Department of Health and Human Services, Center for Disease Control and Prevention, National Center for Chronic Disease Prevention and Health Promotion, Office on Smoking and Health, 2004.

6. World Health Organization. WHO report on the global tobacco epidemic. The M power packaged, 2008. Génova: World Health Organization, 2008. Available from: http://www.who.int/tobacco/mpower/mpower_report_full_2008.

7. Banegas JR, Díez L, González J, Villar F, Rodríguez-Artalejo F. La mortalidad atribuible al tabaquismo comienza a descender en España. Med Clin (Bar) 2005; 28: 124:769-71.

8. Montes A, Pérez M, Gestal JJ. Impacto del tabaquismo sobre la mortalidad en España. Adicciones 2004;16 (2):75-82.

9. García MP, Pérez P, Cruzado JA. Editorial. Presentación del número monográfico: cáncer de Pulmón. Psicooncologia 2006;3(2-3):223-27.

10. American Cancer Society. Cancer Facts and Figures 2002. Atlanta, 2002.

11. Massion PP, Zou Y, Chen H, Jiang A, Coulson $\mathrm{P}, \mathrm{Amos} \mathrm{Cl}$, et al. Smoking-related genomic signatures in non-small cell lung cancer. Am J Respir Crit Care Med 2008; 178:1164-72. Doi:10.1164/rccm.200801$142 \mathrm{OC}$. 
12. Sánchez de Cos J. El cáncer de pulmón en España. Epidemiología, supervivencia y tratamientos actuales. Arch Bronconeumol 2009;45(7):341-8.

13. Villalbí JR, Pasarín MI, Nebot M, Borrell C. Mortalidad por cáncer de pulmón: inicio de declive en los varones de Barcelona. Med Clin (Barc) 2001; 8;117(19):727-31.

14. Bray Fl, Weiderpass E. Lung cancer mortality trends in 36 European countries: Secular trends and birth cohort patterns by sex and region 1970-2007. Int J Cancer 2010, 15;126(6):1454-66. Doi: 10.1002/ ijc. 24855.

15. Zatonski WA, Manczuk M, Powles J, Negri E. Convergence of male and female lung cancer mortality at younger ages in the European union and Russia. Eur J Public Health 2007; 17(5):450-4. Doi: 10.1093/ eurpub/ckl276.

16. Montero C, Rosales M, Otero I, Blanco M, Rodríguez G, Peterga S, et al. Cáncer de pulmón en el Área Sanitaria de A Coruña: incidencia, abordaje clínico y supervivencia. Arch Bronconeumol 2003; 39:209-16.

17. Balibrea JL, Blanco S. Manual de Enfermería y Cirugía Torácica. Madrid: Ediciones Doyma, 2002.

18. Blasco MA, Bonilla F. Superar el Cáncer. Guía práctica de prevención y tratamiento. Barcelona: Martínez Roca, 2001.

19. Rodríguez-Lajusticia L, Villalobos ML, García-Paredes B, Puente J, López-Tarruella $S$, Pérez $P$, et al. Cáncer de pulmón no microcítico: quimioterapia y otros tratamientos sistémicos. Psicooncología 2006; 3:229-247.

20. Krikorian A, Bringas S. Aspectos psicosociales del cáncer de pulmón. Psicooncología 2006;3:347-57.

21. Camacho S. El cáncer de pulmón. En: Die Trill M, editor. Psico-oncología. Madrid: Ades Ediciones, 2003; p. 207-24.

22. DeVita VT, Hellman S, Rosenberg SA. Cancer: Principles and Practice of Oncology. 5th ed. Philadelphia: LippincottRaven publishers, 1997.
23. Murillo M, Pedraza JD. Trastornos psicológicos y de calidad de vida en pacientes de cáncer de pulmón. Psicooncología 2006;3:377-392.

24. Carlsen K, Jensen AB, Jacobsen E, Krasnik $\mathrm{M}$, Johansen $\mathrm{CH}$. Psychosocial aspects of lung cancer. Lung Cancer 2005; 47(3):293300. Doi:10.1016/j.lungcan.2004.08.002.

25. Yoder LH. Lung cancer epidemiology. Medsurg Nurs 2006; 15(3):171-4.

26. Sarna L. Effectiveness of structured nursing assessment of symptom distress in advanced lung cancer. Oncol Nurs Forum 1998; 25(6):1041-8.

27. Becoña E. Guía clínica para ayudar a los fumadores a dejar de fumar. Socidrogalcohol: Valencia, 2004.

28. García-Aranda V, editor. Tabaco, hipertensión y órganos diana. Barcelona: Espaxs Publicaciones Médicas, 1999.

29. Cataldo JK, Dubey S, Prochaska JJ. Smoking cessation: An integral part of lung cancer treatment. Oncology 2010; 78(5-6):289301. Doi: 10.1159/000319937.

30. Chen J, Qi Y, Wampfler JA, Jatoi A, Garces YI, Busta AJ, et al. Effect of cigarette smoking on quality of life in small cell lung cancer patients. Eur J Cancer 2012;48(11):1593-61. Doi: 10.1016/j. ejca.2011.12.002.

31. Walker MS, Vidrine DJ, Gritz ER, Larsen RJ, Yan Y, Govindan R, et al. Smoking relapse during the first year after treatment for early-stage non-small-cell lung cancer. Cancer Epidemiol Biomarkers Prev 2006;15(12):2370-7. Doi: 10.1158/10559965.EPI-06-0509.

32. Parsons A, Daley A, Begh R, Aveyard P. Influence of smoking cessation after diagnosis of early stage lung cancer on prognosis: Systematic review of observational studies with meta-analysis. BMJ 2010;21;340:b5569. Doi: 10.1136/bmj.b5569.

33. Baser S, Shannon VR, Eapen GA, Jimenez CA, Onn A, Lin E, et al. Smoking cessation after diagnosis of lung cancer is associated with a beneficial effect on performance 
status. Chest 2006;130(6):1784-90. Doi: 10.1378/chest.130.6.1784.

34. Chen AM, Chen LM, Vaughan A, Sreeraman R, Farwell DG, Luu Q, et al. Tobacco smoking during radiation therapy for headand-neck cancer is associated with unfavorable outcome. Int J Radiat Oncol Biol Phys 2011;79(2):414-9. Doi:10.1016/j. ijrobp.2009.10.050.

35. Richardson GE, Tucker MA, Venzon DJ, Linnoila RI, Phelps R, Phares JC, et al. Smoking cessation after successful treatment of small-cell lung cancer is associated with fewer smoking-related second primary cancers. Ann Intern Med 1993; 119(5):383-90.

36. Becoña E. Evaluación de la conducta de fumar. En: Graña JL, editor. Conductas Adictivas: Teoría, evaluación y tratamiento. Madrid: Debate, 1994; p.403-54.

37. Prochaska JO, DiClemente CC, Norcross JC. In search of how people change. Applications to addictive behaviors. Am Psychol 1992; 47(9):1102-14. Doi:10.1037/0003066X.47.9.1102.

38. American Psychiatric Association. Diagnostic and statistical manual of mental disorders, 4th ed. revised text. Washington, D.C.: American Psychiatric Association, 2000.

39. Heatherton TF, Kozlowski LT, Frecker RC, Fagerström KO. The Fagerström Test for Nicotine Dependence: A revision of the Fagerström Tolerance Questionnaire. Br J Addict 1991; 86 (9):111927. Doi:10.1111/j.1360-0443.1991. tb01879.x.

40. Becoña E, Vázquez F. The Fagerström Test for Nicotine Dependence in a Spanish sample. Psychol Rep 1998; 83:1455-8. Doi: 10.2466/pr0.1998.83.3f.1455 .

41. Shiffman S, Waters AJ, Hickcox M. The Nicotine Dependence Syndrome Scale: A multidimensional measure of nicotine dependence. Nicotine Tob Res 2004; 6(2): 327-48. Doi:10.1080/146222004200020 2481.
42. Becoña E, López A, Fernández del Río E, Míguez MC, Castro J. Spanish adaptation of the NDSS (Nicotine Dependence Syndrome Scale) and assessment of nicotinedependent in individuals at Primary Care Health Centers in Spain. Span J Psychol 2010;13(2):951-60.

43. Beck AT, Steer RA, Brown GK. BDI-II. Beck Depression Inventory-Second Edition. Manual. San Antonio, TX: The Psychological Corporation, 1996.

44. Sanz J, Perdigón AL, Vázquez C. Adaptación española del Inventario de depresión de Beck-II (BDI-II): 2. Propiedades psicométricas en población general. Clínica y Salud 2003;14:249-80.

45. Spielberger CD, Gorsuch RL, Luchene RE. Cuestionario de ansiedad estado-rasgo. Manual de adaptación española, 4th ed. Madrid: TEA Ediciones, 1971

46. Derogatis LR. SCL-90-R. Cuestionario de 90 síntomas revisado. Manual. Madrid: TEA Ediciones, 2002.

47. Becoña E. Programa para dejar de fumar. Santiago de Compostela: Servicio de Publicaciones da Universidade de Santiago de Compostela, 1993.

48. Becoña E. Programa para dejar de fumar. Vigo: Nova Galicia Edicións, 2007.

49. Becoña $E$, editor. Dependencia del tabaco. Manual de casos clínicos. Madrid: Sociedad Española de Psicología Clínica, Legal y Forense, 2010.

50. Becoña E, Míguez MC. Group behaviour therapy for smoking cessation. J Groups Addict Recover 2008;3:63-78.

51. Velicer WF, Prochaska JO, Rossi JS, Snow, MG. Assessing outcome in smoking cessation studies. Psychol Bull 1992;111(1):2341. Doi:10.1037/0033-2909.111.1.23.

52. West R, Hajek P, Stead L, Stapleton J. Outcome criteria in smoking cessation trials: Proposal for a common standard. Addiction 2005; 100 (3):299-303. Doi: 10.1111/j.1360-0443.2004.00995.x.

53. Hagimoto A, Nakamura M, Morita T, Masui S, Oshima A. Smoking cessation 
patterns and predictors of quitting smoking among the Japanese general population: A 1-year follow-up study. Addiction 2010; 105(1):164-73. Doi: 10.1111/j.13600443.2009.02735.x.

54. Hymowitz N, Cummings KM, Hyland A, Lynn WR, Pechacek TF, Hartwell TD. Predictors of smoking cessation in a cohort of adult smokers followed for five years. Tob Control 1997; 6(2Suppl):57S-62S. Doi:10.1136/tc.6.suppl_2.S57.

55. Zhou X, Nonnemaker J, Sherrill B, Gilsenan A, Coste F, West R. Attempts to quit smoking and relapse: Factors associated with success or failure from the ATTEMPT cohort study. Addict Behav 2009; 34(4):365-373. Doi:10.1016/j. addbeh.2008.11.013.

56. Becoña E, Míguez MC. Dejar de fumar desde casa: "el programa 2001 para dejar de fumar". Psicooncología 2006; 3(23):319-36.

57. Ferguson JA, Patten CA, Schroeder DR, Offord KP, Eberman KM, Hurt RD. Predictors of 6-month tobacco abstinence among 1224 cigarette smokers treated for nicotine dependence. Addict Behav 2003;28:1203-18. Doi:10.1016/S03064603(02)00260-5.

58. Dorner TE, Tröstl A, Womastek I, Groman E. Predictors of short-term success in smoking cessation in relation to attendance at a smoking cassation program. Nicotine Tob Res 2011; 13(11):1068-75. Doi: 10.1093/ntr/ntr179.

59. Crucelaegui A, Nerín I, Sobradiel N, Belmonte A, Novella P, Bernal V, et al. Factores predictores de éxito a los seis meses en fumadores en una unidad de tabaquismo. Prev Tab 2004;6:175-6.

60. Lowman C, Allen J, Stout RL, The Relapse Research Group. Replication and extension of Marlatt's taxonomy of relapse precipitants: Overview of procedures and results. Addiction 1996;91(Suppl):51S-72S. Doi:10.1046/j.1360-0443.91.12s1.16.x.

61. Marlatt GA, Gordon JR, editors. Relapse prevention: Maintenance strategies in the treatment of addictive behaviors. New York: Guilford Press, 1985.

62. Cooley ME, Sarna L, Kotlerman J, Lukanich JM, Jaklitsch M, Green SB, et al. Smoking cessation is challenging even for patients recovering from lung cancer surgery with curative intent. Lung Cancer 2009;66(2):218-25. Doi:10.1016/j.lungcan.2009.01.021.

63. Uchitomi Y, Mikami I, Kugaya A, Akizuki N, Nagai K, Nishiwaki Y, et al. Depression after successful treatment for non small cell lung carcinoma. Cancer 2000;89(5):1172-9. Doi: 10.1002/1097-0142(20000901)89:5< $1172:: A I D-C N C R 27>3.0 . C O ; 2-U$.

64. Fiore MC, Jaén CR, Baker TB, Bailey WC, Benowitz NL, Curry SJ, et al. Treating tobacco use and dependence: 2008 update. Clinical practice guideline. Rockville, MD: United States Department of Health and Human Services, 2008.

65. García-Vera MP, Sanz J. Análisis de la situación de los tratamientos para dejar de fumar basados en terapia cognitivoconductual y en parches de nicotina. Psicooncología 2006;3:260-90. 
